\title{
Emerging Treatments in Eating Disorders
}

\author{
Michael Lutter ${ }^{1}$
}

Published online: 25 May 2017

(C) The American Society for Experimental NeuroTherapeutics, Inc. 2017

\begin{abstract}
Eating disorders (EDs), including anorexia nervosa, bulimia nervosa, and binge-eating disorder, constitute a class of common and deadly psychiatric disorders. While numerous studies in humans highlight the important role of neurobiological alterations in the development of EDrelated behaviors, the precise neural substrate that mediates this risk is unknown. Historically, pharmacological interventions have played a limited role in the treatment of eating disorders, typically providing symptomatic relief of comorbid psychiatric issues, like depression and anxiety, in support of the standard nutritional and psychological treatments. To date there are no Food and Drug Administration-approved medications or procedures for anorexia nervosa, and only one Food and Drug Administration-approved medication each for bulimia nervosa (fluoxetine) and binge-eating disorder (lisdexamfetamine). While there is little primary interest in drug development for eating disorders, postmarket monitoring of medications and procedures approved for other indications has identified several novel treatment options for patients with eating disorders. In this review, I utilize searches of the PubMed and ClinicalTrials.gov databases to highlight emerging treatments in eating disorders.
\end{abstract}

Keywords Anorexia nervosa $\cdot$ Bulimia nervosa $\cdot$

Binge-eating disorder $\cdot$ Treatment

Michael Lutter

michael.lutter@eatingrecovery.com

1 Eating Recovery Center of Dallas, 4716 Alliance Blvd. \#400, Plano, TX 75093, USA

\section{Introduction}

Eating disorder (ED) research is informed by, but distinct from, 2 mature fields of study: the neurobiology of feeding and psychopathology. In the first circumstance, the neurobiological basis of feeding and body weight homeostasis are well understood in preclinical models, such as rodents. However, rodent models are notoriously difficult to model psychosocial stressors, such as Western ideals of thinness, which promote the development of EDs. In the other circumstance, human clinical studies are well-suited to the study of psychological processes contributing to the development of EDs, but oftentimes lack the mechanistic insight necessary for the development of therapeutic interventions.

One alternative approach is to study the action of approved medications to gain mechanistic insight into potential therapeutic targets. While no medications are Food and Drug Administration-approved for treatment of anorexia nervosa (AN), fluoxetine is approved for treatment of bulimia nervosa (BN) and lisdexamfetamine is approved for treatment of binge-eating disorder (BED). Preclinical studies have suggested that activation of serotonin-2C receptors on the midbrain dopamine neurons by fluoxetine or the stimulant $\mathrm{d}$ fenfluramine reduces episodes of binge-like eating in mice [1]. As lisdexamfetamine has similar psychopharmacological properties as d-fenfluramine, it does suggest that both fluoxetine and lisdexamfetamine may target the dopaminergic system as a common biological substrate, perhaps through modulation of reward processing. Clinical studies testing this hypothesis have not yet been reported in humans and will be needed to confirm this hypothesis. Alternatively, several studies have found that elevated rates of impulsivity and behavioral disinhibition contribute to binge-eating episodes in patients with BN and BED [2-6]. Psychopharmacologic studies support a role for fluoxetine and lisdexamfetamine in treating 
binge-eating episodes by reducing impulsivity and behavioral disinhibition in this population [7-11], suggesting another potential pathway to target in the treatment of EDs.

In the current review, I will try to bridge the knowledge gap between basic neuroscience research and clinical studies of disordered eating to highlight novel therapeutic strategies. Even though there are several treatments under evaluation for various of aspects of EDs (e.g., correcting bone loss in $\mathrm{AN}$ ), this review will focus on weight restoration in $\mathrm{AN}$ and decreasing binge eating in $\mathrm{BN}$ and BED.

\section{Experimental Procedures}

\section{Search Criteria}

The PubMed (https://www.ncbi.nlm.nih.gov/pubmed) and ClinicalTrials.gov (https://clinicaltrials.gov/2 databases were searched between 1 January 2017 and 8 March 2017. The search terms "anorexia nervosa treatment", "bulimia nervosa treatment", and "binge-eating disorder treatment" were utilized for the PubMed search, while "anorexia nervosa", "bulimia nervosa", and "binge-eating disorder" were used for ClinicalTrials.gov search. For the PubMed search, "anorexia nervosa treatment" 7460 articles were identified, for "bulimia nervosa treatment" 3360 articles were identified, and for "binge-eating disorder" 1860 articles were identified. Articles for Food and Drugs Administration-approved treatments and behavioral interventions were excluded from consideration. For the ClinicalTrials.gov search, 180 studies were identified for "anorexia nervosa", 170 studies were identified for "bulimia nervosa", and 392 studies for "binge-eating disorder" were identified. Studies without an intervention and studies in "unknown" or "terminated" status were excluded from consideration.

\section{Weight Restoration in AN}

\section{Neuroendocrine}

Starvation alters the levels of numerous circulating hormones. While most of these disturbances are corrected by refeeding, there has been interest in determining if pharmacologically targeting specific endocrine pathways could facilitate recovery from AN [12]. The "hunger" hormone, ghrelin, is one such candidate for the treatment of AN. Ghrelin is an acylated-peptide hormone synthesized in the enteroendocrine cells of the stomach [13], which is released by calorie restriction and stress to stimulate appetite and increase food intake $[14,15]$.

While ghrelin levels appear to be appropriately elevated in AN [16], several studies have found derangements in the regulation of behavioral responses by ghrelin. Whereas high circulating ghrelin levels are associated with activation of brain-reward regions measured by functional magnetic resonance imaging in a food-cue task, patients with AN displayed a negative relationship between ghrelin levels and brain activation in response to high-calorie foods [17]. Furthermore, underweight patients with AN demonstrated progressively decreased ghrelin levels after exposure to palatable food, whereas plasma ghrelin concentrations significantly increased after exposure to palatable food in healthy controls and weightrestored patients with AN, suggesting that dysregulation of ghrelin release may contribute to reduced motivation to consume palatable food in underweight patients with AN [18].

In a pilot study of female patients with restricting-type AN, intravenous ghrelin administration for 14 days increased calorie intake and decreased gastrointestinal (GI) complaints in 4 of 5 patients [19]. Intranasal administration of growth hormone-releasing peptide 2 (a ghrelin receptor agonist) 3 times daily before meals improved body weight and hypoglycemia in a severely emaciated patient with AN [20]. Finally, RM-131, a novel ghrelin receptor agonist, is currently in clinical trials for treatment of AN [21].

Several other endocrine factors are also under investigation for treatment of AN. Oxytocin is a hypothalamic neuropeptide that regulates food intake and levels of oxytocin have long been known to be low in patients with AN $[22,23]$. Polymorphisms in the oxytocin receptor gene and methylation of the oxytocin receptor gene have also been associated with disordered eating in several initial studies [24-26], suggesting a potential link between oxytocin signaling and the development of ED behaviors. While a preliminary study of intranasal oxytocin found that a single dose of oxytocin did not increase short-term calorie intake in patients with AN [27], other studies report that intranasal administration of oxytocin altered attentional bias for fat shape and eating stimuli [28], and also decreased attentional vigilance to disgust in patients with AN [29], suggesting that it might have beneficial effects in other cognitive functions. Additionally, a clinical trial is currently underway to determine if intranasal oxytocin affects smell and food consumption in patients with AN [30]. Finally, androgen deficiency has been associated with hypometabolism of the brain and symptoms of depression, anxiety, and ED thoughts in women with AN [31, 32], and low-dose transdermal testosterone has been shown to improve depressive symptoms, spatial cognition, and lean body mass in initial small studies [33, 34]. Currently, the effect of transdermal testosterone on body mass index in patients with $\mathrm{AN}$ is being investigated in a phase II clinical trial [35].

\section{Neuromodulation}

Recent advances in the field of neuromodulation now offer the hope of nonpharmacological treatment options for an array of mental illnesses, including EDs and associated diagnoses, 
such as major depression and anxiety disorders. Transcranial direct current stimulation (tDCS) is a method for directly modulating the excitability of cortical regions using low-intensity electrical current. A pilot study of tDCS of the left dorsolateral prefrontal cortex (PFC) in 7 patients with AN found that the procedure was well tolerated and associated with a modest short-term benefits in 5 of 7 patients on eating scales, with a sixth patient reporting improvement in depressive symptoms without an effect on the eating scales [36]. These findings support a need for further studies on the potential efficacy of tDCS in AN; currently, 2 studies are registered as actively recruiting $[37,38]$.

Repetitive transcranial magnetic stimulation (rTMS) is another noninvasive approach that allows for stimulation or depression of selected cortical areas. Several initial studies have examined the efficacy of stimulation of the PFC by rTMS in the treatment of AN. A pilot study of 10 individuals with AN found that a single session of rTMS was well tolerated and improved feelings of fullness and anxiety [39]. A study of neuronavigated rTMS in 2 individuals with AN found that 19 to 20 sessions of high-frequency stimulation of the left dorsolateral PFC reduced ED symptomatology [40]. A study of 28 individuals with binge-purge subtype of AN or BN, reported that 20 to 30 sessions of high-frequency stimulation of the dorsomedial PFC resulted in reduced binge/purge behaviors in 16 of 28 participants [41]. A study of 5 patients with treatment-resistant AN found that 20 sessions of highfrequency stimulation of the left dorsolateral PFC resulted in significant improvement in eating pathology at 6-month follow in 3 of 5 patients [42]. Finally, a study of single-session stimulation of the left dorsolateral PFC in 60 patients with AN found a trend $(p=0.056)$ toward improvement in core ED symptoms [43], supporting the need for follow-up studies of multiple-session stimulation. Two studies are currently registered for the study of rTMS in AN $[44,45]$.

In addition to tDCS and rTMS, which are noninvasive, deep brain stimulation (DBS) is another neuromodulatory technique currently under investigation in the treatment of AN. DBS allows for direct modulation of the neuronal activity of deep structures in the brain by neurosurgical implantation of electrodes. DBS is an established therapy for the treatment of refractory cases of movement disorders and obsessivecompulsive disorder (OCD). Given the shared neural circuitry of AN and OCD, some have hypothesized that DBS may be effective for the treatment of AN as well [46, 47]. Several studies have provided support for this hypothesis by reporting a potential role for DBS in the treatment of severe, enduring cases of AN. Stimulation of the nucleus accumbens by DBS in 4 patients with severe AN found an improvement in body weight restoration with body weight $>85 \%$ at last follow-up in all individuals [48]. A case report of a women with $\mathrm{AN}$ who received DBS of the ventral striatum for severe comorbid OCD found improvements in the ED pathology in addition to reduction in OCD symptoms [49]. DBS of the subcallosal cingulate in 6 patients with severe, treatment-resistant AN found that 4 of 6 patients reported improvements in mood and anxiety symptoms and 3 of 6 patients reported improvements in body weight restoration and quality of life [50]. In the largest study to date, an open-label trial of 16 treatmentrefractory patients with AN receiving DBS of the subcallosal cingulate found significant improvements in body mass index, depression, anxiety, and affective regulation at 1-year followup [51]. Currently, 3 clinical trials are underway to study the role of DBS in the treatment of AN [52-54].

\section{Preclinical Models of Restricted Eating}

While the risk of developing AN is highly heritable, the lack of genetically validated rodent models of voluntary food restriction have limited attempts to identify potential medications based on pathophysiology. Our group has recently identified the first 2 rare, highly penetrant genetic variants that increase the risk of developing an EDs [55]. Importantly, mice that are genetically manipulated to replicate the disease-associated human variants display several behavioral phenotypes relevant to EDs, including decreased willingness to work for a high-fat diet after being fasted overnight [56, 57]. These mouse lines with impaired behavioral responses to a negative energy state are the first monogenic models of AN and offer a unique opportunity for screening of novel pharmaceutical compounds. Based upon a bioinformatic analysis of potential genetic pathways affected in these mouse models, we identified rosiglitazone as a potential novel medication to treat symptoms of AN [58]. Of note, rosiglitazone has been associated with body weight gain when used to treat patients with diabetes mellitus and has also been studied as a potential treatment for major depression [59], which is frequently comorbid with AN. Esrra-null mice administered rosiglitazone display increased food intake, body weight, and adipose tissue compared with vehicle-treated littermate mice (data not shown). While further behavioral and neurobiological characterization of these mice is necessary before translational studies are initiated, it does demonstrate the potential benefit of the approach (Tables 1 and 2).

\section{Additional Approaches}

Genetic variants in the epoxide hydrolase 2 gene have been associated with the risk of developing AN [60]. The epoxide hydrolase 2 protein catalyzes the conversion bioactive epoxides on polyunsaturated fatty acids into corresponding diols and is important for a number of metabolic pathways, including cholesterol synthesis [61], suggesting that omega- 6 fattyacid supplementation may affect the clinical course of AN [62]. Several other diverse approaches are also currently under consideration as well, including cannabinoid receptor signaling [63, 64], probiotics [65], and fish oil [66]. 
Table 1 Synopsis of emerging treatments for weight restoration in Anorexia Nervosa

\begin{tabular}{|c|c|c|c|}
\hline Intervention & Classification & Proposed mechanism of action & Supporting evidence \\
\hline RM-131 & Gut neuroendocine & Appetite stimulating ghrelin receptor agonist & $\begin{array}{l}\text { Successful Phase II clinical trials proof-of-concept } \\
\text { trial on } 22 \text { patients with AN }\end{array}$ \\
\hline Oxytocin & Pituitary hormone & Affects social and feeding behaviors & $\begin{array}{l}\text { Changes in attention to food/shape stimuli, clinical } \\
\text { trial on-going }\end{array}$ \\
\hline Testorterone & Sex hormone & $\begin{array}{l}\text { Corrects hypometabolism in brain of } \\
\text { underweight patients }\end{array}$ & Increases lean body mass in two RCTs \\
\hline tDCS & Neuromodulation & Modulates excitation of cortical regions & $\begin{array}{l}\text { Improvement in eating and depressive symptoms } \\
\text { in } 5 / 7 \text { patients }\end{array}$ \\
\hline rTMS & Neuromodulation & Stimulation or depression of cortical regions & $\begin{array}{l}\text { Improvement in eating symptoms in } 4 \text { case series, } \\
\text { trend toward benefit in } 1 \text { RCT }\end{array}$ \\
\hline DBS & Neuromodulation & Stimulation of subcallosal cingulate & Several case series, one open-label trial of 16 patients \\
\hline Rosiglitazone & PPARg-agonist & Increases mitochondrial biogenesis in brain & $\begin{array}{l}\text { Increases food intake and body weight in one } \\
\text { rodent model of restriction }\end{array}$ \\
\hline Omega- 6 fatty acids & Nutraceutical & Reduction in inflammation & Clinical study on-going \\
\hline Cannabinoid signaling & Neurotransmission & Stimulate appetite, reduce inflammation & Clinical study on-going \\
\hline Lactobacillus reuteri & Probiotic & Normalizes bowel flora, improves gut function & Clinical study on-going \\
\hline
\end{tabular}

Abbrevations: $t D C S$ transcranial direct current stimulation, $r T M S$ repetitive transcranial magnetic stimulation, DBS deep brain stimulation, PPARg peroxisome proliferator-activated receptor gamma, $R T C$ randomized controlled trial

\section{Binge Eating in $\mathrm{BN}$ and $\mathrm{BED}$}

\section{Neuroendocrine}

While not all patients with $\mathrm{BN}$ and BED are overweight, efforts to find new treatments for obesity have contributed to the understanding of appetite regulation with important implications for binge eating. One particularly important area of research is in satiety hormones, which are secreted by the GI tract in response to nutrients to help terminate meals. Since impairments in satiety have been associated with overeating in

Table 2 Synopsis of emerging treatments for binge-eating episodes in Bulimia Nervosa and Binge-Eating Disorder

\begin{tabular}{|c|c|c|c|}
\hline Intervention & Classification & Proposed mechanism of action & Supporting evidence \\
\hline $\mathrm{CCK}$ & Gut neurohormone & Increases satiety & $\begin{array}{l}\text { Reduced post-prandial levels in BN, clinical study of } \\
\text { CCK receptor agonist on-going }\end{array}$ \\
\hline GLP-1 & Gut neurohormone & Increases satiety & $\begin{array}{l}\text { Reduced post-prandial levels in BN, liraglutide } \\
\text { FDA-approved for weight loss, clinical study } \\
\text { on-going in BN and BED }\end{array}$ \\
\hline PYY & Gut neurohormone & Increases satiety & Reduced post-prandial levels in $\mathrm{BN}$ \\
\hline Topiramate & Antiepileptic & Suppresses appetite & $\begin{array}{l}\text { Mono-therapy associated with weight loss in obesity, } \\
\text { combination with phenteramine reduced binge-eating } \\
\text { in a case series, clinical study on-going }\end{array}$ \\
\hline Zonisamide & Antiepileptic & Suppresses appetite & $\begin{array}{l}\text { Reduces binge-eating in BED in } 1 \text { RTC and in BN in } \\
1 \text { open-label pilot study }\end{array}$ \\
\hline Naltrexone, nalmefene & $\begin{array}{l}\text { Mu-opioid } \\
\text { antagonist }\end{array}$ & Suppresses appetite & $\begin{array}{l}\text { Naltrexone-bupropion combination FDA approved for } \\
\text { weight loss, nalmefene improves BED in a case report, } \\
\text { clinical studies on-going }\end{array}$ \\
\hline tDCS & Neuromodulation & Modulates excitation of cortical regions & Positive effects 1 case series in BED and $1 \mathrm{RCT}$ in $\mathrm{BN}$ \\
\hline rTMS & Neuromodulation & Stimulation or depression of cortical regions & Positive effects in 4 small studies, 1 failed RCT in BN \\
\hline Lorcaserin & Neurotransmission & Agonist of serotonin $2 \mathrm{C}$ receptor & $\begin{array}{l}\text { FDA approved for weight loss, reduces binge-episodes in } \\
\text { mouse model of binge-eating }\end{array}$ \\
\hline Erythromycin & Antibiotic & Prokinetic agent & Clinical study on-going \\
\hline Memantine & Neurotransmission & Modulates signaling on NMDA receptor & Clinical study on-going \\
\hline Baclofen & Neurotransmission & GABA-B receptor agonist & Clinical study on-going \\
\hline
\end{tabular}

Abbreviations: $C C K$ cholecystokinin, GLP-1- glucagon-like peptide 1, PYY polypeptide YY, $t D C S$ transcranial direct current stimulation, $r T M S$ repetitive transcranial magnetic stimulation, $R T C$ randomized controlled trial 
clinical populations, targeting satiety responses may represent a new target for treatment of binge-eating.

While numerous satiety hormones have been identified, most research has focused on cholecystokinin (CCK), glucagon-like peptide 1 (GLP-1), and polypeptide YY (PYY) [67]. CCK is released by L cells of the intestine in response to lipids and proteins, and CCK has numerous postprandial functions, including decreasing appetite, slowing gastric emptying, and increasing gall bladder stimulation [68]. Postprandial levels of CCK have been reported to be blunted in patients with $\mathrm{BN}[69,70]$. One clinical study is currently investigating the role of novel CCK receptor agonist in BN [71].

GLP-1 is a cleavage product of the glucagon gene and is secreted primarily by the enteroendocrine L cells of the intestines in response to many nutrients, including monosaccharides, peptides and amino acids, and fatty acids [72]. GLP-1 has numerous functions, including slowing of gastric emptying, increasing insulin release, and suppressing appetite. Pharmacologic agonists of GLP-1 receptor signaling have been approved for the treatment of diabetes and, more recently, chronic weight management [73]. Several studies have reported blunted postprandial levels of GLP-1 in patients with $\mathrm{BN}[74,75]$, although it is unclear if these differences directly contribute to the development of disordered eating or are a consequence of it. One study is currently registered to examine the potential benefits of the GLP-1 agonist liraglutide on binge eating in $\mathrm{BN}$ and $\mathrm{BED}[76]$.

PYY is also synthesized by enteroendocrine $\mathrm{L}$ cells in the intestine in response to multiple nutrients and has similar effects on reducing GI track motility, increasing insulin secretion, and suppressing appetite [77]. Several studies have examined the PYY levels in patients with EDs with mixed results. Some studies have found a blunted increase in PYY levels after test meals in patients with BN [78-80], while no difference in PYY levels were observed in female patients with BED [81]. Furthermore, there was a negative correlation between postprandial PYY levels and binge frequency in women [80], although it is again unclear if altered PYY levels contribute to the development of disordered eating behaviors or are a consequence of it. While several clinical trials are investigating the use of intranasal PYY in the treatment of obesity, no trials are currently registered to examine PYY agonists in the treatment of EDs.

\section{Antiepileptic Drugs}

Several medications originally developed for the treatment of seizures have been found to affect body weight. Topiramate modulates the activity glutamate and $\gamma$-aminobutryic acid receptors and voltage-dependent sodium channels, although the precise mechanism by which it causes weight loss is not well understood [82]. While topiramate alone promotes weight loss in patients with metabolic disorders, such as type 2 diabetes, it was associated with a significantly increased risk of serious adverse events, including liver failure, serious injuries or falls, kidney stones, and viral infection with leukopenia, making it less appealing as a monotherapy for treatment of obesity [83]. More recently an extended release formulation of topiramate and the stimulant phentermine has been approved for the treatment of obesity primarily through appetite suppression [84]. A small study found that the topiramate/phentermine combination reduced binge-eating in 2 patients with BED, supporting a need for larger studies [85]. One study is currently testing topiramate/phenteramine in the treatment of BED and BN (NCT02553824). In addition to topiramate, another antiepileptic drug, zonisamide, has been associated with weight loss in clinical populations [86]. Furthermore, 2 small trials of zonisamide in patients with BED with obesity [87] and with BN [88] found significant reductions in ED behaviors, although the discontinuation rate was very high in both studies. No current clinical trials are registered for zonisamide in BED or BN.

\section{Opioid Antagonists}

While inhibition of mu-opioid receptor signaling has long been known to decrease "hedonic" feeding in rodents [89], most clinical trials attempting to use the mu-opioid antagonist naltrexone in the treatment of obesity and binge eating have been disappointing [90-92]. However, in recent years the use of naltrexone as part of combination therapies has been more widely investigated as researchers have come to appreciate redundancies in feeding systems [93]. One such combination, naltrexone with the antidepressant bupropion, has been approved for the treatment of obesity demonstrating a $3 \%$ to $7 \%$ decrease in body weight primarily through a reduction in calorie intake [94]. As depression is frequently comorbid with $\mathrm{BED}$, the naltrexone-bupropion combination is especially attractive to clinicians hoping to minimize polypharmacy in their patients. Additionally, other formulations of opioid antagonists, including intranasal naloxone and nalmefene, have shown some beneficial effects in BED [95, 96]. Currently, 1 clinical trial is actively investigating the efficacy of naltrexone-bupropion in BED [97] and 1 trial examining intranasal naloxone in BED [98].

\section{Neuromodulation}

Similar to AN, several research groups are currently investing nonpharmacological approaches to the treatment of binge eating. A recent study found that a single session of tDCS of the dorsolateral PFC reduced urges to binge in 39 patients with BN [99], while a similarly designed study reported reduction in urges to binge in 30 patients with BED [100]. Several preliminary studies of women with BN suggested that rTMS of 
the left dorsolateral PFC [101-103] and dorsomedial PFC [104] reduced food cravings, but a randomized doubleblinded study of 47 women with $\mathrm{BN}$ found no clinical benefit of rTMS to the left dorsolateral PFC [105].

Several registered clinical trials are currently following up on the potential for neuromodulation to treat BED. One group investigating low-frequency $(1 \mathrm{~Hz})$ rTMS of the dorsomedial PFC is also studying high frequency $(20 \mathrm{~Hz})$ stimulation of the dorsomedial PFC in $\mathrm{BN}$ [106]. A separate study is investigating 1-session 10-Hz stimulation of the dorsolateral PFC in BN [107]. Another group is measuring the effect of $10-\mathrm{Hz}$ stimulation of the dorsolateral PFC on binge-eating episodes in patients with BED [108]. Direct current stimulation of the PFC is also currently under investigation in the treatment of $\mathrm{BN}$ and BED [109].

\section{Preclinical Models of Binge-Like Eating}

At present there are no monogenic models of BED as no specific genomic variants have been linked to the risk of developing $\mathrm{BN}$ or BED. However, there are behavioral models that are useful as preclinical models of binge-like eating. One model that has been particularly informative involves repetitive limited access to palatable food, such as high-fat food, that produces binge-like bouts of eating (up to $50 \%$ of the daily calorie intake within $2 \mathrm{~h}$ ) in both rats and mice [110, 111]. One important feature of this model is that it does not require forced calorie restriction or stress to induce the bingelike episodes. This model has identified several potential novel therapies, including DBS of the nucleus accumbens [112, 113], the serotonin 2C receptor agonist lorcaserin [105], and the nociceptin receptor antagonist LY2940094 [114].

\section{Additional Approaches}

Erythromycin, used for its nonantibiotic effect to stimulate GI motility in patients, is currently being investigated in patients with $\mathrm{BN}$ to determine if it reduces binge/purge frequency [115]. Memantine, which modulates the glutamatergic $N$ methyl-D-aspartate receptor, is being tested for efficacy in reducing binge/frequency and body dysmorphia in patients with BN [116]. Finally, a clinical trial is testing the potential of the $\gamma$-aminobutryic acid-B receptor agonist baclofen to decrease binge frequency in BN and BED [117].

\section{Conclusions}

While EDs have historically been under studied relative to their burden on society, new insights from related fields have identified several potential therapeutic interventions. Research from the field of feeding and body weight homeostasis has found several endocrine factors that that can stimulate (e.g., ghrelin) or suppress (e.g., GLP-1, PYY) appetite. These factors are now being tested for the treatment of restricted and binge eating, respectively. Central nervous system drugs originally approved for other indications, such as antiepileptic drugs and opioid antagonists, may reduce binge-eating episodes. Neuromodulation techniques developed for treatment of mood and anxiety disorders show promising results as an adjunctive treatment for AN, BN, and BED. Finally, the explosion in genetic research has led to novel rodent models of ED-like behaviors that allow for rapid preclinical screening of compounds. It is now incumbent upon funding agencies to evaluate rigorously the efficacy of these emerging therapies.

Required Author Forms Disclosure forms provided by the authors are available with the online version of this article.

\section{References}

1. V. Xu P, He Y, Cao X, et al. Activation of serotonin $2 \mathrm{C}$ receptors in dopamine neurons inhibits binge-like eating in mice. Biol Psychiatry 2016; 81: 737-747.

2. Sysko, R, Ojserkis, R, Schebendach, JE, Evans, SM, Hildebrandt TB, Walsh, BT. Impulsivity and test meal intake among women with bulimia nervosa. Appetite 2017; 112: 1-8.

3. Coffino JA, Orloff NC, Hormes JM. Dietary restraint partially mediates the relationship between impulsivity and binge eating only in lean individuals: the importance of accounting for body mass in studies of restraint. Front Psychol 2016;7:1499.

4. Reas DL, Pedersen G, Rø Ø. Impulsivity-related traits distinguish women with co-occurring bulimia nervosa in a psychiatric sample. Int J Eat Disord 2016;49:1093-1096.

5. Merlotti E, Mucci A, Volpe U, et al. Impulsiveness in patients with bulimia nervosa: electrophysiological evidence of reduced inhibitory control. Neuropsychobiology 2013;68:116-123.

6. Kaisari P, Dourish CT, Higgs S. Attention deficit hyperactivity disorder (ADHD) and disordered eating behaviour: a systematic review and a framework for future research. Clin Psychol Rev 2017;53:109-121.

7. Vickers SP, Goddard S, Brammer RJ, Hutson PH, Heal DJ. Investigation of impulsivity in binge-eating rats in a delaydiscounting task and its prevention by the d-amphetamine prodrug, lisdexamfetamine. J Psychopharmacol 2017 Feb 1.

8. Silva $\mathrm{H}$, Iturra $\mathrm{P}$, Solari A, et al. Fluoxetine response in impulsiveaggressive behavior and serotonin transporter polymorphism in personality disorder. Psychiatr Genet 2010;20:25-30.

9. Downe, KA, Goldfein, JA, Devlin, MJ. Restraint, hunger, and disinhibition following treatment for binge-eating disorder. Int $\mathrm{J}$ Eat Disord 2009;42:498-504.

10. McElroy SL, Mitchell JE, Wilfley DE, et al. Lisdexamfetamine dimesylate effects on binge eating behaviour and obsessivecompulsive and impulsive features in adults with binge eating disorder. Eur Eat Disord Rev 2016;24:223-231.

11. Kemps E, Wilsdon A. Preliminary evidence for a role for impulsivity in cognitive disinhibition in bulimia nervosa. J Clin Exp Neuropsychol 2010;32:515-521.

12. Schorr M, Miller KK. The endocrine manifestations of anorexia nervosa: mechanisms and management. Nat Rev Endocrinol 2017; 13: 174-186.

13. Strader AD, Woods SC. Gastrointestinal hormones and food intake. Gastroenterology 2005;128:175-191. 
14. Lutter M, Sakata I, Osborne-Lawrence S, et al. The orexigenic hormone ghrelin defends against depressive symptoms of chronic stress. Nature Neurosci 2008;11:752-753.

15. Perello M, Sakata I, Birnbaum S, et al. Ghrelin increases the rewarding value of high-fat diet in an orexin-dependent manner. Biol Psychiatry 2010;67:880-886.

16. Prince AC, Brooks SJ, Stahl D, Treasure J, Treasure J. Systematic review and meta-analysis of the baseline concentrations and physiologic responses of gut hormones to food in eating disorders. Am J Clin Nutr 2009;89:755-765.

17. Holsen LM, Lawson EA, Christensen KA, Klibanski A, Goldstein JM. Abnormal relationships between the neural response to highand low-calorie foods and endogenous acylated ghrelin in women with active and weight-recovered anorexia nervosa. Psychiatry Res 2014;223:94-103.

18. Monteleone AM, Monteleone P, Dalle Grave R, et al. Ghrelin response to hedonic eating in underweight and short-term weight restored patients with anorexia nervosa. Psychiatry Res 2016;235: 55-60.

19. Hotta M, Ohwada R, Akamizu T, et al. Ghrelin increases hunger and food intake in patients with restricting-type anorexia nervosa: a pilot study. Endocr J 2009;56:1119-1128.

20. Haruta I, Fuku Y, Kinoshita K, et al. One-year intranasal application of growth hormone releasing peptide- 2 improves body weight and hypoglycemia in a severely emaciated anorexia nervosa patient. J Cachexia Sarcopenia Muscle 2015;6:237-241.

21. Motus Therapeutics, Inc.; Massachusetts General Hospital. Phase 2 pilot study to evaluate the safety and efficacy of RM-131 administered to females with anorexia nervosa. Available at: http:/ clinicaltrials.gov/show/NCT01642550. Accessed Jan 12, 2017.

22. Demitrack MA, Lesem MD, Listwak SJ, et al. CSF oxytocin in anorexia nervosa and bulimia nervosa: clinical and pathophysiologic considerations. Am J Psychiatry 1990;147:882-886.

23. Lawson EA, Donoho DA, Blum J, et al. Decreased nocturnal oxytocin levels in anorexia nervosa are associated with low bone mineral density and fat mass. J Clin Psychiatry 2011;72:15461551.

24. Kim Y-R, Kim JH, Kim MJ, Treasure J. Differential methylation of the oxytocin receptor gene in patients with anorexia nervosa: a pilot study. PLOS ONE 2014;9:e88673.

25. Kim Y-R, Kim JH, Kim C-H, Shin JG, Treasure J. Association between the oxytocin receptor gene polymorphism (rs53576) and bulimia nervosa. Eur Eat Disord Rev 2015;23:171-178.

26. Acevedo SF, Valencia C, Lutter M, McAdams CJ. Severity of eating disorder symptoms related to oxytocin receptor polymorphisms in anorexia nervosa. Psychiatry Res 2015;228:641-648.

27. Kim YR, Eom JS, Yang JW, Kang J, Treasure J. The impact of oxytocin on food intake and emotion recognition in patients with eating disorders: a double blind single dose within-subject crossover design. PLOS ONE 2015;10:e0137514.

28. Kim Y-R, Kim C-H, Cardi V, et al. Intranasal oxytocin attenuates attentional bias for eating and fat shape stimuli in patients with anorexia nervosa. Psychoneuroendocrinology 2014;44:133-142.

29. Kim Y-R, Kim C-H, Park JH, Pyo J, Treasure J. The impact of intranasal oxytocin on attention to social emotional stimuli in patients with anorexia nervosa: a double blind within-subject crossover experiment. PLOS ONE 2013;9:e90721.

30. Fondation Lenval. Oxytocin and incitement to use olfactory stimuli in restrictive anorexia nervosa. Available at: http://clinicaltrials. gov/show/NCT02333500. Accessed Jan 12, 2017.

31. Miller KK, Wexler T, Zha AM, et al. Androgen deficiency: association with increased anxiety and depression symptom severity in anorexia nervosa. J Clin Psychiatry 2007;68:959-965.

32. Miller KK, Deckersbach T, Rauch SL, et al. Testosterone administration attenuates regional brain hypometabolism in women with anorexia nervosa. Psychiatry Res 2004;132:197-207.
33. Miller KK, Grieco KA, Klibanski A. Testosterone administration in women with anorexia nervosa. J Clin Endocrinol Metab 2005;90:1428-1433.

34. Miller KK, Meenaghan E, Lawson EA, et al. Effects of risedronate and low-dose transdermal testosterone on bone mineral density in women with anorexia nervosa: a randomized, placebo-controlled study. J Clin Endocrinol Metab 2011;96:2081-2088.

35. National Institute of Mental Health Massachusetts General Hospital. Hormonal factors in the treatment of anorexia nervosa. Available at: http://clinicaltrials.gov/show/NCT01121211. Accessed Jan 12, 2017.

36. Khedr EM, Elfetoh NA, Ali AM, Noamany M. Anodal transcranial direct current stimulation over the dorsolateral prefrontal cortex improves anorexia nervosa: a pilot study. Restor Neurol Neurosci 2014;32:789-797.

37. Bambino Gesù Children's Hospital. New treatment perspectives in eating disorders: the efficacy of non-invasive brain-directed treatment. Available at: http://clinicaltrials.gov/show/NCT02382497. Accessed Jan 12, 2017.

38. University Hospital, Montpellier. Transcranial Direct Current Stimulation (tDCS) and Anorexia Nervosa (STAR). Available at: http://clinicaltrials.gov/show/NCT02734108.. Accessed Jan 12, 2017.

39. Van den Eynde F, Guillaume S, Broadbent H, Campbell IC, Schmidt U. Repetitive transcranial magnetic stimulation in anorexia nervosa: a pilot study. Eur Psychiatry 2013;28:98-101.

40. McClelland J, Bozhilova N, Nestler S, et al. Improvements in symptoms following neuronavigated repetitive transcranial magnetic stimulation (rTMS) in severe and enduring anorexia nervosa: findings from two case studies. Eur Eat Disord Rev 2013;21:500506.

41. Dunlop K, Woodside DB, Lam E, et al. Increases in frontostriatal connectivity are associated with response to dorsomedial repetitive transcranial magnetic stimulation in refractory binge/purge behaviors. Neuroimage Clin 2015;8:611-618.

42. McClelland J, Kekic M, Campbell IC, Schmidt U. Repetitive transcranial magnetic stimulation (rTMS) treatment in enduring anorexia nervosa: a case series. Eur Eat Disord Rev 2016;24: 157-163.

43. McClelland J, Kekic M, Bozhilova N, et al. A randomised controlled trial of neuronavigated repetitive transcranial magnetic stimulation (rTMS) in anorexia nervosa. PLOS ONE 2016;11: e0148606.

44. University Hospital, Rouen. rTMS and body shape perception (STIMOREX). Available at: http://clinicaltrials.gov/show/ NCT01717079. Accessed Jan 12, 2017.

45. University Health Network, Toronto. High-frequency vs. lowfrequency vs. sham DMPFC-rTMS for bulimia and anorexia nervosa. Available at: http://clinicaltrials.gov/show/ NCT02702167. Accessed Jan 12, 2017.

46. Oudijn MS, Storosum JG, Nelis E, Denys D. Is deep brain stimulation a treatment option for anorexia nervosa? BMC Psychiatry 2013;13:277.

47. Kisely S, Hall K, Siskind D, Frater J, Olson S, Crompton D. Deep brain stimulation for obsessive-compulsive disorder: a systematic review and meta-analysis. Psychol Med 2014;44:3533-3542.

48. Wu H, Van Dyck-Lippens PJ, Santegoeds R, et al. Deep-brain stimulation for anorexia nervosa. World Neurosurg 2013;80: S29.e1-10.

49. McLaughlin NCR, Didie ER, Machado AG, et al. Improvements in anorexia symptoms after deep brain stimulation for intractable obsessive-compulsive disorder. Biol Psychiatry 2013;73:e29-e31.

50. Lipsman N, Woodside DB, Giacobbe P, et al. Subcallosal cingulate deep brain stimulation for treatment-refractory anorexia nervosa: a phase 1 pilot trial. Lancet 2013;381:1361-1370. 
51. Lipsman N, Lam E, Volpini M, et al. Deep brain stimulation of the subcallosal cingulate for treatment-refractory anorexia nervosa: 1 year follow-up of an open-label trial. Lancet Psychiatry 2017;4: 285-294.

52. University of Oxford; Oxford Health NHS foundation trust. Pilot study of deep brain stimulation for severe anorexia nervosa. Available at: http://clinicaltrials.gov/show/NCT01924598. Accessed Jan 12, 2017.

53. Beijing Tiantan Hospital; Beijing Pins Medical Co., Ltd. PINS stimulator system to treat severe anorexia nervosa. Available at: http://clinicaltrials.gov/show/NCT02263404. Accessed Jan 12, 2017.

54. Tang-Du Hospital. Deep brain stimulation of nucleus accumbens to treat severe anorexia nervosa. Available at: http://clinicaltrials. gov/show/NCT02593695. Accessed Jan 12, 2017.

55. Cui H, Moore J, Ashimi SS, et al. Eating disorder predisposition is associated with ESRRA and HDAC4 mutations. J Clin Invest 2013;123:4706-4713.

56. Cui H, Lu Y, Khan MZ, et al. Behavioral disturbances in estrogenrelated receptor alpha-null mice. Cell Rep 2015;11:344-350.

57. Lutter M, Khan MZ, Satio K, et al. The eating-disorder associated HDAC4A778T mutation alters feeding behaviors in female mice. Biol Psychiatry 2017;81:770-777.

58. Strum JC, Shehee R, Virley D, et al. Rosiglitazone induces mitochondrial biogenesis in mouse brain. J Alzheimers Dis 2007;11: 45-51.

59. Colle R, de Larminat D, Rotenberg S, et al. PPAR- $\gamma$ agonists for the treatment of major depression: a review. Pharmacopsychiatry 2017;50:49-55.

60. Scott-Van Zeeland AA, Bloss CS, Tewhey R, et al. Evidence for the role of EPHX2 gene variants in anorexia nervosa. Mol Psychiatry 2014;19:724-732.

61. Shih PB, Yang J, Morisseau C, et al. Dysregulation of soluble epoxide hydrolase and lipidomic profiles in anorexia nervosa. Mol Psychiatry 2016;21:537-546.

62. Shih PB. Integrating multi-omics biomarkers and postprandial metabolism to develop personalized treatment for anorexia nervosa. Prostaglandins Other Lipid Mediat 2017 Feb 21

63. Odense University Hospital. Cannabinoid receptor (CB1) agonist treatment in severe chronic anorexia nervosa. Available at: http:// clinicaltrials.gov/show/NCT00760695. Accessed Jan 12, 2017.

64. Cannabics Pharmaceuticals Inc. Cannabics capsules as treatment to improve cancer related CACS in advanced cancer patients. Available at: http://clinicaltrials.gov/show/NCT02359123. Accessed Jan 12, 2017.

65. BioGaia AB; Pediatric Department Clinical Hospital Centre Sestre milosrdnice Gastroenterology, Hepatology and Nutrition Ward. The role of Lactobacillus reuteri in children and adolescents with anorexia nervosa. Available at: http://clinicaltrials.gov/show/ NCT02004288. Accessed Jan 12, 2017.

66. Nationwide Children's Hospital. Treatment of anxiety and anorexia nervosa in adolescents (TAANA). Available at: http:// clinicaltrials.gov/show/NCT01933243. Accessed Jan 12, 2017.

67. Asarian L, Bachler T. Neuroendocrine control of satiation. Horm Mol Biol Clin Investig 2014;19:163-192.

68. Dockray GJ. Cholecystokinin. Curr Opin Endocrinol Diabetes Obes 2012;19:8-12.

69. Hannon-Engel SL. Regulating satiety in bulimia nervosa: the role of cholecystokinin. Perspect Psychiatr Care 2012;48:34-40.

70. Hannon-Engel SL, Filin EE, Wolfe BE. CCK response in bulimia nervosa and following remission. Physiol Behav 2013;122:56-61.

71. St. Luke's-Roosevelt Hospital Center; GlaxoSmithKline. Effect of a CCK-1R agonist on food intake in humans (GSK). Available at: http://clinicaltrials.gov/show/NCT00600743. Accessed Jan 12, 2017.
72. Bodnaruc AM, Prud'homme D, Blanchet R, Giroux I. Nutritional modulation of endogenous glucagon-like peptide-1 secretion: a review. Nutr Metab 2016;13:92.

73. Burcelin R, Gourdy P. Harnessing glucagon-like peptide-1 receptor agonists for the pharmacological treatment of overweight and obesity. Obes Rev 2017;18:86-98.

74. Dossat AM, Bodell LP, Williams DL, Eckel LA, Keel PK. Preliminary examination of glucagon-like peptide-1 levels in women with purging disorder and bulimia nervosa. Int J Eat Disord 2015;48:199-205.

75. Naessen S, Carlstrom K, Holst JJ, Hellstrom PM, Hirschberg AL. Women with bulimia nervosa exhibit attenuated secretion of glucagon-like peptide 1, pancreatic polypeptide, and insulin in response to a meal. Am J Clin Nutr 2011;94:967-972.

76. Universiti Kebangsaan Malaysia Medical Centre. Influence of appetite related hormones in binge eating behaviour among the overweight and obese. Available at: http://clinicaltrials.gov/show/ NCT01739049. Accessed Jan 12, 2017.

77. Spreckley E, Murphy KG. The L-cell in nutritional sensing and the regulation of appetite. Front Nutr 2015;2:23.

78. Kojima S, Nakahara T, Nagai N, et al. Altered ghrelin and peptide YY responses to meals in bulimia nervosa. Clin Endocrinol 2005;62:74-78.

79. Monteleone P, Martiadis V, Rigamonti AE, et al. Investigation of peptide YY and ghrelin responses to a test meal in bulimia nervosa. Biol Psychiatry 2005;57:926-931.

80. Rigamonti AE, Sartorio A, Scognamiglio P, et al. Different effects of cholestyramine on postprandial secretions of cholecystokinin and peptide YY in women with bulimia nervosa. Neuropsychobiology 2014;70:228-234.

81. Geliebter A, Hashim SA, Gluck ME. Appetite-related gut peptides, ghrelin, PYY, and GLP-1 in obese women with and without binge eating disorder (BED). Physiol Behav 2008;94:696-699.

82. Walker MC, Sander JW. Topiramate: a new antiepileptic drug for refractory epilepsy. Seizure 1996;5:199-203.

83. Paravattil B, Wilby KJ, Turgeon R. Topiramate monotherapy for weight reduction in patients with type 2 diabetes mellitus: a systematic review and meta-analysis. Diabetes Res Clin Pract 2016;114:9-14.

84. Smith SM, Meyer M, Trinkley KE. Phentermine/topiramate for the treatment of obesity. Ann Pharmacother 2013;47:340-349.

85. Guerdjikova AI, Fitch A, McElroy SL. Successful treatment of binge eating disorder with combination phentermine/topiramate extended release. Prim Care Companion CNS Disord 2015;17.

86. Antel J, Hebebrand J. Weight-reducing side effects of the antiepileptic agents topiramate and zonisamide. Handb Exp Pharmacol 2012;209;433-466.

87. McElroy SL, Kotwal R, Guerdjikova AI, et al. Zonisamide in the treatment of binge eating disorder with obesity: a randomized controlled trial. J Clin Psychiatry 2006;67:1897-1906.

88. Guerdjikova AI, Blom TJ, Martens BE, Keck PE, McElroy SL. Zonisamide in the treatment of bulimia nervosa: an open-label, pilot, prospective study. Int J of Eat Disord 2013;46:747-750.

89. Recant L, Voyles NR, Luciano M, Pert CB. Naltrexone reduces weight gain, alters " $\beta$-endorphin", and reduces insulin output from pancreatic islets of genetically obese mice. Peptides 1980;1:309-313.

90. Malcolm R, O'Neil PM, Sexauer JD, Riddle FE, Currey HS, Counts C. A controlled trial of naltrexone in obese humans. Int $J$ Obes 1984;9:347-353.

91. Maggio CA, Presta E, Bracco EF, et al. Naltrexone and human eating behavior: A dose-ranging inpatient trial in moderately obese men. Brain Res Bull 1985;14:657-661.

92. Atkinson RL, Berke LK, Drake CR, Bibbs ML, Williams FL, Kaiser DL. Effects of long-term therapy with naltrexone on body weight in obesity. Clin Pharmacol Ther 1985;38:419-422. 
93. Plodkowski RA, Nguyen Q, Sundaram U, Nguyen L, Chau DL, St Jeor S. Bupropion and naltrexone: a review of their use individually and in combination for the treatment of obesity. Expert Opin Pharmacother 2009;10:1069-1081.

94. Naltrexone/bupropion: Contrave(R); naltrexone SR/bupropion SR. Drugs R D 2010;10:25-32.

95. McElroy SL, Guerdjikova AI, Mori N, Keck PE. Psychopharmacologic treatment of eating disorders: emerging findings. Curr Psychiatry Rep 2015;17:573.

96. Marazziti D, Piccinni A, Baroni S, Dell'Osso L. Effectiveness of nalmefene in Binge Eating Disorder: a case report. J Clin Psychopharmacol 2016;36:103-104.

97. Yale University; Yale School of Medicine. Treatment of binge eating disorder in obesity: naltrexone/bupropion combination versus placebo. Available at: http://clinicaltrials.gov/show/ NCT02317744. Accessed Jan 12, 2017.

98. Lightlake Sinclair Ltd. Clinical trial on binge eating disorder, treatment with naloxone spray (BED). Available at: http://clinicaltrials. gov/show/NCT01567670. Accessed Jan 12, 2017.

99. Kekic M, McClelland J, Bartholdy S, et al. Single-session transcranial direct current stimulation temporarily improves symptoms, mood, and self-regulatory control in bulimia nervosa: a randomised controlled trial. PLOS ONE 2017;12:e167606.

100. Burgess EE, Sylvester MD, Morse KE, et al. Effects of transcranial direct current stimulation (tDCS) on binge eating disorder. Int J Eat Disord 2016;49:930-936.

101. Hausmann A, Mangweth B, Walpoth M, et al. Repetitive transcranial magnetic stimulation (rTMS) in the double-blind treatment of a depressed patient suffering from bulimia nervosa: a case report. Int J Neuropsychopharmacol 2004;7:371-373.

102. Van den Eynde F, Claudino AM, Mogg A, et al. Repetitive transcranial magnetic stimulation reduces cue-induced food craving in bulimic disorders. Biol Psychiatry 2010;67:793-795.

103. Sutoh C, Koga Y, Kimura H, et al. Repetitive transcranial magnetic stimulation changes cerebral oxygenation on the left dorsolateral prefrontal cortex in bulimia nervosa: a near-infrared spectroscopy pilot study. Eur Eat Disord Rev 2016;24:83-88.

104. Downar J, Sankar A, Giacobbe P, Woodside DB, Colton PA. Unanticipated rapid remission of refractory bulimia nervosa, during high-dose repetitive transcranial magnetic stimulation of the dorsomedial prefrontal cortex: a case report. Front Psychiatry 2012;3:30.

105. Gay A, Jaussent I, Sigaud T, et al. A lack of clinical effect of highfrequency rTMS to dorsolateral prefrontal cortex on bulimic symptoms: a randomised, double-blind trial. Eur Eat Disord Rev 2016;24:474-481.
106. University Health Network, Toronto. High-frequency vs. lowfrequency vs. sham DMPFC-rTMS for bulimia and anorexia nervosa. Available at: https://clinicaltrials.gov/show/ NCT02702167. Accessed Mar 9, 2017.

107. Centre Hospitalier Universitaire de Saint Etienne. Transcranial magnetic stimulation and bulimic craving. Available at: https:// clinicaltrials.gov/show/NCT02547246. Accessed Mar 9, 2017.

108. Federal University of São Paulo. The effects of repetitive transcranial magnetic stimulation in obese people with BED. Available at: https:/clinicaltrials.gov/show/NCT02180984. Accessed Mar 9, 2017.

109. Bambino Gesù Children's Hospital. New treatment perspectives in eating disorders: the efficacy of non-invasive brain-directed treatment. Available at: https:/clinicaltrials.gov/show/NCT02382497. Accessed Mar 9, 2017.

110. Corwin RL. Binge-type eating induced by limited access in rats does not require energy restriction on the previous day. Appetite 2004;42:139-142.

111. S. Czyzyk TA, Sahr AE, Statnick MA. A model of binge-like eating behavior in mice that does not require food deprivation or stress. Obesity 2010;18:1710-1717.

112. T. Halpern CH, Tekriwal A, Santollo J, et al. Amelioration of binge eating by nucleus accumbens shell deep brain stimulation in mice involves D2 receptor modulation. J Neurosci 2013;33: 7122-7129.

113. U. Doucette WT, Khokhar JY, Green AI. Nucleus accumbens deep brain stimulation in a rat model of binge eating. Transl Psychiatry 2015;5:e695.

114. W. Statnick MA, Chen Y, Ansonoff M, et al. A novel nociceptin receptor antagonist LY2940094 inhibits excessive feeding behavior in rodents: a possible mechanism for the treatment of binge eating disorder. J Pharmacol Exp Ther 2016;356:493-502.

115. National Institute of Mental Health; New York State Psychiatric Institute. Effectiveness of antibiotic treatment for reducing binge eating and improving digestive function in bulimia nervosa. Available at: http://clinicaltrials.gov/show/NCT00304187. Accessed Jan 12, 2017.

116. McLean Hospital. An open label trial of memantine in the treatment of bulimia nervosa and body dysmorphic disorder. Available at: http://clinicaltrials.gov/show/NCT01038128. Accessed Jan 12, 2017.

117. National Institute of Mental Health; New York State Psychiatric Institute. Effectiveness of baclofen in the treatment of people with bulimia nervosa or binge eating disorder. Available at: http:// clinicaltrials.gov/show/NCT00320047. Accessed Jan 12, 2017. 